\title{
Cost-Sharing Payment Plans and Cost-Saving Green Management Practices: The Case of Seasonal Employees in Turkey's Small- and Medium-Sized Touristic Hotels
}

\author{
Özge Demiral* \\ Nigde Ömer Halisdemir University
}

*Corresponding Author: Özge Demiral, Nigde Ömer Halisdemir University, Department of Business Administration, Nigde, Turkey

\begin{abstract}
Inline with the rapid increase in people's environmental awareness, how to create an environmentally cost-saving culture in business organizations has become an emerging question that has been intensively gaining a considerable research domain in the business and management literature and engaging the attention of practitioners in the field. A new strand of the interest has focused on what encourage employees to behave green in the hotel industry in which customers, employees, and hoteliers seem to be not caring about pro-environmental practices. Starting from this unpleasant consistency in the preferences of customers, employees, and hoteliers, this study purposes to explore whether employees within cost-sharing payment plans tend to behave eco-friendlier. The data were collected from 114 seasonal tourism employees working in 21 small- and medium-sized hotels located in Antalya, the largest city on the Mediterranean coast in Turkey. Results from mean-score comparisons reveal some signs indicating that, in business organizations like hotels, employee payment plans reflecting the costs and profits can motivate employees to embrace simple but efficient going-green practices. Consequently, it can be inferred that costsaving pro-environmental practices can benefit both environment and organizations. This suggestion provides new insights for scholars, managers/owners, and policy-makers about what can be done for enhancing the sustainability, responsibility and green attributions of business and management operations.
\end{abstract}

Keywords: Social responsibility, Organizational sustainability, Environmental awareness, Green business, Green management, Green HRM, Hotel industry, Seasonal employees, Turkey.

\section{INTRODUCTION}

There has been a well-known fact that the world is increasingly facing environmental issues related to global climate change, ozone depletion, pollution, high consumption of resources and increasing amount of solid waste, etc. ${ }^{[1]}$. As a major part of the society, business organizations have been reducing the quantities of natural resources and the quality of the natural environment, through the resource consumption, greenhouse emissions, and wastage production associated with their business processes. In order to lessen their destructive impacts on the natural environment, organizations are now aware of the necessity that they must adopt environmentally sustainable business operations ${ }^{[2]}$.

Globally, the ever-growing concerns about environmental problems have created a huge multidisciplinary literature. However, in business and management literature, extant studies seem to be restricted to traditional objectives of business organizations such as profit-maximization ignoring the environmental concerns that have risen recently. On the other hand, in line with the increasing individual environmental consciousness which is characterized by the extent to which a person engages in pro-environmental behaviors, some recent research in the relevant literature has started to deal with the green implications underscoring the both cost-saving and efficiency-driving benefits of going green in business organizations ${ }^{[2][3]}$.Now, it is understood well that businesses that are behind the green wave trend tend to lose competitiveness in today's business environments where both consumers and producers are more conscious environmentally and becoming more capable to distinguish between green washing tactics and true environmental concerns of businesses. Therefore, business organizations need to create value by building environmental thinking into their overall business strategies ${ }^{[4][5][6]}$. By doing so, they may build a sustainability-based competitive advantage which has both internal (strengths and weakness of the resources businesses have) and external 
(opportunities and threats that the environment exposes) dynamics affecting their business strategies $^{[7][8]}$.

In the conventional approach, business managers and owners acknowledge that integrating environmental concern into business strategies is a disadvantage in reaching organizational goals and it is harmful for their businesses. However, recently, a new overwhelming wisdom has emerged suggesting that integrating environmental concerns into economic goals benefits both business and the environment. In this new approach, going green is no longer seen a cost of doing business, rather, it is accepted one of the main drivers of organizational innovation, productivity and efficiency ${ }^{[9][10]}$. Therefore, it is important to identify the match of cost-saving and environmentally-friendly behaviors of employees, managers, and owners in business organizations.

As the predominant part of the tourism sector, lodging and hotel industries were considered not causing much environmental degradation. Nevertheless, recent research has shown that the hospitability industry is destructive to the natural environment as much as the manufacturing industry is. Therefore, many hotel enterprises, especially those in developed countries, are now advocating for green assessments and certification. However, in developing countries, like Turkey, this has not been the case that, except a few governmental regulations, most part of hotels has not yet adopted any green practices and hence they have never enjoyed the benefits of going green ${ }^{[11][12][13]}$.

Hotels with green management practices such as saving water, reducing energy use, and reducing solid waste can have a hand in conserving and preserving the environment and meanwhile they can get benefits of reduced costs and increased profits ${ }^{[11]}$. All these mean that going green can benefit both business organizations and environment. Within this new win-win strategy, i.e., a better environmental and organizational performance, this study purposes to explore whether cost-saving green behaviors and motivations of employees working with cost- and profit-sharing plans differ from those who are paid constantly under a cost- and profit-independent payment plan. The study utilizes a survey data collected from 114 seasonal tourism employees working in 21 small- and medium-sized hotels located in Antalya, the largest touristic city on the Mediterranean coast in Turkey. The remainder of this paper is structured as follows: In Section 2 conceptual framework of the study is described. In Section 3, theoretical framework is outlined and hypothesis is constructed. Section 4 illustrates research design by introducing the sample and survey instrument. After results are presented and discussed in Section 5, the study concludes with some discussion on findings and future insights for both practical and managerial implications in the last section.

\section{CONCEPTUAL FRAME WORK}

\subsection{Organizational Sustainability and Social Responsibility}

It is observed that businesses those solely focus on the profit-maximization and size-enhancement objectives, cannot satisfy their customers, stakeholders, and partners. Business organizations are now expected to be socially responsible that also helps in making them sustainable. Today, what make businesses sustainable is an important question that has intensively attracted the interest of not only researchers in business and management literature but also those of practitioners and policy-makers in the field.

The paradigm of sustainable organization has shifted sequentially, first from the definition of large and profit-maximizing businesses to ones that effectively engage with external stakeholders, and employees; later on, to those that have innovation and trust cultures and get ready instantly to the contemporary changes. Recently, we have been experiencing a new paradigm shift that sustainable businesses are those that concern about environmental issues and take green business initiatives. This 'green image' of a business is acknowledged as a prestige which can also influence the commitments and satisfactions of their customers and employees with high environmental awareness[10][5].

The operations of business organizations, regardless what and how they are doing, have impacts on both societies and the natural environment. Therefore, they have been compelled to tackle the issues of organizational sustainability and corporate social responsibility for years in line with the rapid rise of global consciousness about natural environment[14]. Consistently, organizations have developed a variety of strategies for combining the external goals such as organizational sustainability and corporate social responsibility to their internal objectives like profit maximization, competitiveness, and growth. 
Within the pro-environmental business organizations and stressing the importance of caring about the well-being of others and about the environment, Glavas and Kelley (2014: 171)[15]define corporate social responsibility as "the strategies and operating practices that a business develops in operationalizing its relationships with and impacts on the well-being of all of its key stakeholders and the natural environment". This definition ties corporate social responsibility to organizations' economic fundamentals in an ecologically sustainability aspect based on several new concepts of total quality environmental management, sustainable competitive strategies, eco-friendly technology transfer, and reducing the impact of populations on ecosystems[16]. Organizational sustainability, by definition, means "keep the business going" or "future proofing of organizations". Beyond these colloquial aspects, organizational sustainability, in fact, is caring about the needs of future generations and hereby it refers to "achieving success today without compromising the needs of the future" [17].

It can be inferred from these definitions that both organizational sustainability and social responsibility have green business aspects. This interaction between organizational sustainability and corporate social responsibility brings about two questions: Can business organizations be both environmentally sustainable and profitable? and what makes organizations sustainable? In order to answer these questions, it is necessary to take a closer look at the concepts of green business and green human resource management.

\subsection{Green Businesses and Green Human Resource Management}

Čekanavičius et al. (2014: 76)[18] define green business as an business organization that promises its committed to the principles of environmental sustainability in its operations, strives to use renewable resources and tries to minimize the negative environmental impacts of its activities. Green business practices include waste sorting, turning off unused electronic appliances, less printing, using public transportation or carpooling, eco-cleaning, green building, reducing power waste, green packaging, no-smoking around office, organizing training programs and seminars for their employees about green business, etc. that can be summarized by four Rs, namely, reduction, reuse, recycling, and recovery.

The question here is about how each of those Rs can be achieved. In the green business literature, it is widely accepted that organizations become greener voluntarily. Considering the implications and practices, in fact, organizational eco-change orientation will only be realized through stringent state regulation[19]. In an organizational perspective, green business initiative is an inclusive process in where customers, suppliers, and governments take part[20][18]. This process charges new functions to human resource management (HRM) departments that also need to be green. Green human resource management (green HRM) refers to a set of HRM practices that organizations adopt to improve workplace and workforce green by managing the environmental sources economically and promoting sustainability awareness within organizations[21].

Green HRM has important functions that help in creating green workforce and environmentalist culture including green recruitment, green performance appraisal, green training and development, green compensation, green employee relations, etc. These functions highlight the necessity of some green initiatives like green building, paperless office, energy conservation, recycling and waste disposal, etc.[21].All these functions and green initiatives of HRM consequently embody some strategies to motivate or enforce employees to behave green and become involved in environmentallyfriendly activities [22][23][24]. One potential alternative is to let the benefits of employees be affected by the costs that can be avoided through cost-saving behaviors within organizations.

\subsection{Cost-Sharing and Cost-Saving Plans}

Cost-sharing (and profit-sharing) plans distribute some part of organizational costs (and profits) to employees. As the common cases in practice, profit distributions can be either cash or deferred payments[25]: Cash distribution plans provide full payments soon after profits have been determined whereas in deferred payments, current profits accumulate in employee accounts and cash payment is only made to employees when they no longer work in the organizations for different reasons like becoming disabled, leaving the organization, retiring or dying[26].

Since the organizational profits and costs also depend on overall business environments, it can be hard for both employees and employers to see the link between their working efforts and corporate profits/costs. Therefore, some organizations have adopted cost-saving plans particularly that pay 
bonuses to employees depending upon the money organizations have saved through increased efficiency of their operations. Because employees often have more control over the costs of jobs they are doing, it is easier for them to see the connection between their works and cost reductions [26].Since shared profit is dependent on costs, the profit-sharing programs, are expected to reflect the increasing cost-saving behaviors among employees. Some of these cost-saving behaviors are related to individual eco-friendly attitudes of employees, but consequently can create common organizational culture towards going green based on some initiatives like going paperless (soft copy, software, email-connections, etc.) buying and using reusable products, reducing water and energy use, lowering utility costs, tele working, carpooling with colleagues, etc. within green businesses and green HRM frameworks.

\subsection{Hotel Industry Case}

Tourism, recognized as one of the world's largest industries, continues to expand at a rapid rate. The number of international tourist arrivals reached 1.2 billion people in 2016, in which France and the United States have the highest shares followed by Spain, China, and Italy. World's top tourism spenders in 2016 are China, the United States, Germany, the United Kingdom and France that the total international tourism expenditures of these 5 countries' in 2016 exceeded 550 billion United States Dollars[12]. However, the benefits of tourism are often accompanied by many negative environmental and social impacts such as air and water pollution, degradation and depletion of natural resources, biodiversity loss, labor issues, encroachment and overbuilding[27].

The hotel industry, as the main pillar of the whole tourism sector, is widely dependent on resources that environmentally friendly management practices are seen as urgent needs in the sector[20].It is possible that as hoteliers make their hotels greener they can save money, reduce waste, and operate more efficiently which consequently can help them in increasing customer and employee satisfaction. In the global context, even not strong, it is observed recently that eco-friendly accommodation bookings have increased and leading travel fare aggregators and travel meta search engines for lodging reservations have started to put eco-friendly search filter on hotels combined together with several global accreditation criteria[13][27].In addition to direct cost benefits, there are also indirect benefits of going green including but not limited to competitive advantage by being a leader in the sector, customer loyalty (image and prestige effect), employee retention, awards and recognition, regulatory compliance, risk management and increased brand value[27] that all increase the value of the intangible assets of hotels consequently.

Over the past two decades, Turkey, as a country surrounded by sea on three sides, by the Black Sea in the north, the Mediterranean Sea in the south and the Aegean Sea in the west together with an internal one, the Sea of Marmara, has made considerable investments in the tourism sector, especially in those of leisure travels. The transport and lodging infrastructure and the efficiency of services and communication network systems are able to meet all the requirements of contemporary tourism. The accommodation industry of Turkey includes wide range hotels in every segments and concepts. Briefly, Turkey with its great diversity of natural resources, historical treasures, cultural values, lifestyle, and heritages, offers a wide selection of products that can supply the demand of miscellaneous travelers. As a good indicator of the development of tourism and lodging industry, the numbers of hotels, incoming domestic/foreign tourists and travel agencies have rapidly increased over time in Turkey[28].

The hotel industry, in general, has an immense potential for incorporating green management and green HRM practices by utilizing cost-saving culture within the hotel organizations[27].Even though this is true in Turkey as well, the potential has not been realized for a number of reasons and barriers. One important reason stems from the fear of losing competitiveness since it is widely believed that green management practices that reflect green hotel reputations are not actually cared by the customers. Supporting this premise, a small-scale survey conducted among Turkish hotel guests exhibits that they really do not care about the environmentally-friendly features of the hotels while they chose where to stay, as shown in Table 1. 
Cost-Sharing Payment Plans and Cost-Saving Green Management Practices: The Case of Seasonal Employees in Turkey's Small- and Medium-Sized Touristic Hotels

Table 1. Reasons Given by Turkish Guests* for Hotel Selection (N: 395)

\begin{tabular}{|c|c|c|c|c|c|}
\hline \multirow[b]{2}{*}{$\begin{array}{c}\text { What is the most important factor } \\
\text { affecting your decision } \\
\text { whenchoosing a hotel to stay in } \\
\text { your summertime break? } \\
\text { (check only one which is most } \\
\text { important to you) }\end{array}$} & \multicolumn{5}{|c|}{ Customers of... } \\
\hline & 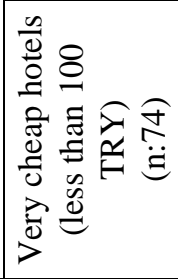 & 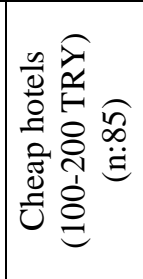 & 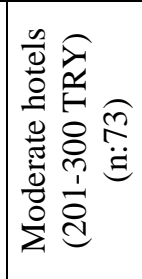 & 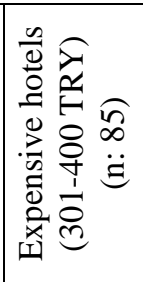 & 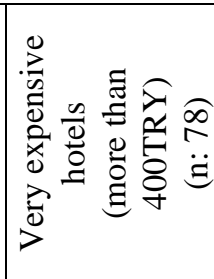 \\
\hline 1.Price & $38 \%$ & $41 \%$ & $8 \%$ & $13 \%$ & $15 \%$ \\
\hline 2. Reputation (number of star) & $19 \%$ & $13 \%$ & $19 \%$ & $19 \%$ & $27 \%$ \\
\hline 3.Services & $17 \%$ & $18 \%$ & $33 \%$ & $23 \%$ & $21 \%$ \\
\hline 4.Convenience or location & $14 \%$ & $16 \%$ & $21 \%$ & $17 \%$ & $16 \%$ \\
\hline 5. Package deal & $14 \%$ & $9 \%$ & $6 \%$ & $8 \%$ & $12 \%$ \\
\hline 6. Previous experience & $12 \%$ & $3 \%$ & $13 \%$ & $18 \%$ & $9 \%$ \\
\hline 7. Green hotel & $0 \%$ & $1 \%$ & $0 \%$ & $2 \%$ & $0 \%$ \\
\hline
\end{tabular}

Notes: The data were obtained from a survey of 395 domestic (Turkish) customers stayed during August 2017 in the 10 all-inclusive touristic hotels (2per each price segment) located in Antalya city of Turkey. The month August has usually the highest rates. The prices are daily walk-in rates per adult in the period. TRY refers to Turkish Lira. Ranking the factors from 1 to 7 is based on the preferences of very cheap hotel customers. Price levels were classified by the Author.

Another barrier to green management based-on energy efficiency is the concerns about the costs of such initiatives. Moreover, the lack of environmental awareness is a strong barrier as well, hindering hoteliers to implement greener management practices since they believe that compliance with laws and local standards is enough to make their facilities environmentally responsible. Therefore, it is important for governmental institutions, to motivate and/or enforce hotels to be eco-friendly by controlling and inspecting them regularly[18][19][20].

As a common tendency, like the other countries attracting many tourists, management departments of hotels in Turkey, do not have strict policies for green management. Even though some hotels engage in several environmentally-friendly practices and implement green management initiatives they, especially small- and medium-sized hotels, still seem to be having challenges to motivate and encourage their employees to go green. Table 2 shows that nobody among 114 seasonal hotel employees take environmentally-friendliness features of hotels into consideration while they looking for hotels to work for.

Table 2. Reasons Given by Hotel Employees for Hotel Selection to Work (N:114)

\begin{tabular}{|l|c|}
\hline $\begin{array}{l}\text { What is the most important factor affecting your decision when seeking a hotel to } \\
\text { work for? (check only one) }\end{array}$ & Number of participants \\
\hline 1. Seasonality/full-year operating & 35 \\
\hline 2. Compensation and other benefits & 27 \\
\hline 3. Reputation in the area & 15 \\
\hline 4. Number of stars & 12 \\
\hline 5. Opportunities provided & 8 \\
\hline 6. Size (guest capacity) & 6 \\
\hline 7. Location (closeness to beaches, city center, employee's home) & 5 \\
\hline 8. Size (number of employees) & 3 \\
\hline 9. References/recommendations & 3 \\
\hline 10. Eco-friendliness and green hotel. & 0 \\
\hline
\end{tabular}

Notes: The data were obtained from a simple questionnaire conducted among114 seasonal employees that are referred to the 'sample' throughout the study. The Author compromised the 10 factors with these 114 employees.

This unpleasant accordance of the attitudes and behaviors of hotel employees and guests seem to be strengthened by the lack of concrete evidence in the related literature for hotel businesses about how to tackle issues in motivating employees to go green. Starting from this shortage of evidence, this study tries to identify whether sharing the costs exposed by not going green can enforce employees to carry out their behaviors in cost-saving and eco-friendly manners. 
When linking business operations with environmental degradation, studies tend to focus on the destructive impacts of production, distribution, consumption and recycling activities of manufacturers and farmers. Therefore, in general, enterprises operating in agriculture, forestry and fishing; mining and quarrying; and manufacturing industries are commonly blamed for the decline of the quality of the natural environment. Consistently, the research interests seem to have focused green manufacturing [3] and neglected service sectors like tourism. This negligence is based on the traditional recognition that tourism sectors, like many other services, are attributed to so-called "chimneyless" industry (e.g.[29]) to describe the harmlessness and cleanness of the sector. Besides this production-side approach, recently an increasing number of studies has adopted the consumptionside aspect and emphasize the harmful influences of tourism sectors on environmental quality. Some of these studies focus on the hotel industries [30][31], but still focusing on the impacts of whole sectors with a macro approach. Adopting a holistic approach but with a micro-level experimental strategy, this study combines organizational sustainability, social responsibility, green businesses and green HRM and examines whether cost-sharing implications can be an efficient way to reduce the redundant management and operating costs in case of seasonal employees in small- and medium-sized touristic hotels located in Turkey.

\section{THEORETICAL FRAMEWORK AND HYPOTHESIS}

Mathematically, we can show the net profit of a business organization in a production industry as follows[32]:

$$
\begin{aligned}
\text { Net profit }= & {[(\text { quantity sold })(\text { unit selling price })]-} \\
& {[(\text { quantity sold })(\text { unit variable cost })+\text { total fixed costs }] }
\end{aligned}
$$

In a hotel business case, this relationship can be notated as,

$$
\begin{aligned}
N P & =T R-T C \\
T C & =T F C+T V C \Rightarrow \\
N P & =[(N o G)(N o D)(P)]-[(T F C)+(N o G)(U V C)] .
\end{aligned}
$$

Where NP is net profit, TR is total revenue, TC is total cost, NoG is number of guests, NoD is the number of day guests stayed, Pis daily price per each guest, UVC is unit variable cost (the cost that depends on the number of guests) and TFC is total fixed costs (the cost that is independent of the number of guests). Equation (2) indicates that NP of a hotel business depends on TR and TC. Employees are not supposed to be affecting the TR directly since they are unable to affect the number of guests and the prices that are usually determined and managed by the owners and/or managers. TFC consist of the business start-up costs like hotel building, room architecture, pool and beach designs, restaurant appliance, etc. and remains same at all levels of guest number, in other words, it is independent of, or unrelated to, guest number. Even though the green management also can be important in TFC in terms of green hotel perspective that, for instance, the building, itself, might be constructed environmentally, seasonal employees have no impact on it. Therefore, the only cost component that employees can influence on is TVC which, as a result, determines NP. Again, because of the assumption that NoG is determined externally by the tourism market, UVC is the only cost component that employees can affect.

Cost-sharing and profit-sharing implications of hotel businesses are expected to be affecting the costsaving behaviors of employees by going green. This, as a result, can affect UVC and TVC. The logic behind this suggestion is that there is some cost that can be saved and when employees aware of the implication that as they save cost them, actually everyone, will earn more. Therefore, the hypothesis is constructed as follows: "Cost-saving green management behaviors are more adopted by employees who earn under the cost-sharing and/or profit-sharing payment plans than those who have a constant amount of compensation which is independent of organizational cost and profit". The hypothesis is tested in case of small- and medium-sized hotel businesses in Antalya, one of the most attractive touristic cities of Turkey for especially leisure travelers from all around the world.

\section{RESEARCH APPROACH: SAMPLE AND SURVEY INSTRUMENT}

The study uses a data collected through a micro-scaled survey conducted from July to August 2017 in 21 small- and medium-sized hotels located in Antalya. Main characteristics of hotels surveyed are presented in Table 3., followed by demographics of respondents shown in Table 4. 
Cost-Sharing Payment Plans and Cost-Saving Green Management Practices: The Case of Seasonal Employees in Turkey's Small- and Medium-Sized Touristic Hotels

Table 3. Main Characteristics of Hotels Surveyed $*(N: 21)$

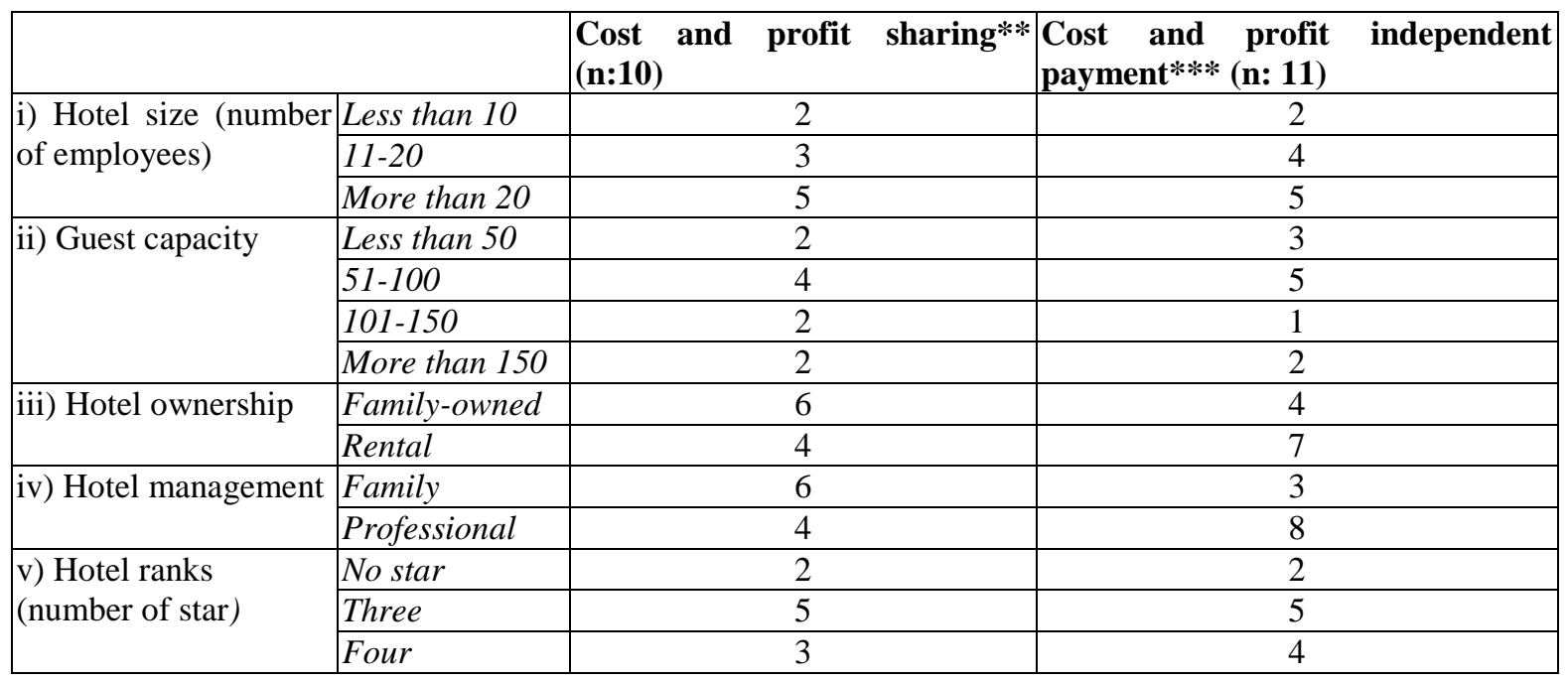

Notes: *All the hotels included in the sample are located in Antalya city's coast. They are all operating seasonally for about six months (usually from May to October). **Employees are paid a regular wage (usually legal minimum wage)or equivalent benefits and plus a predetermined share of net earnings remained after all the cost reduced.*** Employees are paid only a certain and prearranged amount of money which is around the average amount paid in the region. This amount dealt before the season starts is independent of cost and profit of the hotel, hereby owners and/or managers bear all risk that can stem from tourism market.

Table 4.Main Demographics of Respondents (N: 114)

\begin{tabular}{|c|c|c|c|}
\hline Age category & Frequency & Formal education level & Frequency \\
\hline Under 20 & 18 & Elementary school degree & 53 \\
\hline $21-30$ & 42 & High School degree & 44 \\
\hline $31-40$ & 39 & Bachelor's degree & 17 \\
\hline Over 40 & 15 & & \\
\hline Gender & Frequency & Working department & Frequency \\
\hline Male & 71 & Service* & 81 \\
\hline Female & 43 & Non-service** & 33 \\
\hline
\end{tabular}

*Directly engaged in services that guests get (receptions, restaurants, cafés/bars and pools/beaches). **Their primary job assignments are related to the maintenance of the utilities and some managerial services like cleaning and technical services, kitchen and security jobs, accounting, advertising, buying-selling, HRM implications, etc.

Table 5. Survey Items Asked Respondents to Rank

1) Recycling (cardboards, papers, cans, plastics, bottles, etc.).

2) Using reusable utensils rather than disposable ones.

3) Purchasing/using post-consumer recyclable products (office supplies, hand towels, etc.).

4) Serving and having a proper portion of food to reduce food waste.

5) Paperless policy including use of electronic software or system (e-copy, e-mail, etc.).

6) Non-smoking policy (non-smoking throughout the property) for indoor air quality.

7) Placing green live plants on property for the quality of indoor air

8) Using environmentalcleaning products (e.g. organic and/or natural certified products, etc.).

9) Cleaning AC units regularly

10) Using automatic sensor lighting on the property.

11) Using energy star rated equipment (refrigerator, copier, etc.).

12) Using high energy efficient lighting throughout the property.

13) Setting temperature appropriately in office, kitchen, etc.

14) Using sky- lights to maximize natural light throughout the property.

15) Towel and linen reuse program in guest rooms.

16) Using automatic and low-flow fixtures (toilet, sink, etc.).

17) Recycling water for reuse (e.g. irrigation, sprinkling, etc.).

18) Landscaping with native plants to minimize water consumption.

19) Using public transportation or carpooling to reduce personaltravel costs.

20) Paperless recruitment process (websites announcement, online interviewing, etc.) 
Cost-Sharing Payment Plans and Cost-Saving Green Management Practices: The Case of Seasonal Employees in Turkey's Small- and Medium-Sized Touristic Hotels

Notes: The items were adapted and translated from those of Kim (2009)[34]and Kim and Choi (2013)[35] into Turkish. Some instructive illustrations about the items were attached to the surveys, for a better comprehension

Among the common green practices in the lodging industry, like hotels, water conserving fixtures and linen-reuse programs are among the main practices[18][20][27][33]. Linking these green hotel implications to green management, specifically green HRM functions[21][34][35], several new practices can be included. Consequently, the survey is constructed based on 20 items shown in Table 5.Regarding the importance level of green practices to them, participants were asked to indicate their level of agreement to each of the items according to the following 5-point Likert-type scale: (1) unimportant, (2) little important (3) moderately important, (4) very important, (5) extremely important. In fact, these items are about general green business and green management practices that are directly or indirectly related to HRM in organizations, hotels in our case.

\section{RESUlts AND DisCUSSION}

In order to explore whether the importance of these green management practices itemized in Table 5 significantly differ between two employee groups, namely employees with cost/profit sharing plans (Group 1) and those getting a constant payment (Group 2), paired-sample t-test for two independent groups was employed and results are reported in Table 6.

\begin{tabular}{|c|c|c|c|c|c|}
\hline \multicolumn{6}{|c|}{ Mean-scores of scales:(1) unimportant...(5) extremely important } \\
\hline Items & Group 1 & Group 2 & Items & Group 1 & Group 2 \\
\hline 1) & 2.5 & $3.1^{(\mathrm{b})}$ & 11) & 3.3 & $3.5^{(\mathrm{a})}$ \\
\hline 2) & 3.0 & 2.7 & 12) & $3.5^{(a)}$ & 3.3 \\
\hline 3) & 2.3 & 2.5 & 13) & $3.5^{(a)}$ & $3.7^{(\mathrm{a})}$ \\
\hline 4) & $3.7^{(\mathrm{a}),(\mathrm{b})}$ & 3.0 & 14) & 2.6 & 3.0 \\
\hline 5) & $4.1^{(\mathrm{a}),(\mathrm{b})}$ & $3.5^{(\mathrm{a})}$ & 15) & 2.9 & 2.7 \\
\hline 6) & $3.8^{(\mathrm{a})}$ & $3.5^{(\mathrm{a})}$ & 16) & $3.6^{(\mathrm{a})}$ & $3.5^{(\mathrm{a})}$ \\
\hline 7) & $4.1^{(\mathrm{a})}$ & $4.2^{(\mathrm{a})}$ & 17) & $3.8^{(\mathrm{a}),(\mathrm{b})}$ & 3.1 \\
\hline 8) & 2.9 & 3.0 & 18) & $3.8^{(\mathrm{a}),(\mathrm{b})}$ & 3.2 \\
\hline 9) & 2.7 & 3.0 & 19) & 3.0 & 2.7 \\
\hline 10) & 2.5 & 2.7 & 20) & 2.1 & 2.0 \\
\hline \multicolumn{4}{|c|}{ Overall mean-score (items 1-20) } & 3.2 & 3.1 \\
\hline
\end{tabular}

Notes: Group 1 and 2 consist of employees working under cost/profit sharing and cost/profit independent constant payment plans, respectively. (a):Tendency of the group towards cost-saving green behavior is high in general, i.e. mean-score is either above or equal to 3.5. (b): Tendency of the group towards cost-saving green behavior is significantly $(p<0.05)$ higher than the other group.

Results of t-test showed that the mean-scores in the items 5, 6, 7, 13 and 16were relatively high in both groups, whereas, the mean-scores of employees in Group 1 in the items 4, 5, 17 and 18 are significantly higher than those in Group 2. The only item that Group 2 has a higher value than that of Group 1 is the item 1, and moreover, the overall difference between mean-scores of two groups is not statistically significant. As a result, the support to the hypothesis is found limited. Yet, there are signs indicating that employee payment plans reflecting cost and profit of business can help in reducing the cost, and therefore, in increasing the profit. It can be inferred that cost-saving pro-environmental practices can benefit both environment and organizations. This suggestion provides new insights for scholars, managers/owners and policy-makers about what can be done for enhancing sustainable, responsible and greener business and management operations. Results from the pairwise t-test for two-group demographics (gender and working departments), and the analysis of variance for threegroup demographics (age, and education level), revealed no significant difference over demographics of the participants.

In Turkey, the tourism industry is somewhat supported by governmental incentives in order to help in developing the sector and increasing tourist satisfaction. Small and medium-sized enterprises in tourism sectors are also supported to some extent within the stimulating programs covering youth entrepreneurship and overall employment campaigns. Particularly, according to the Law for the Encouragement of Tourism, some of the certified tourism investments have been taking advantages of lower rates in payment for utilities such as electricity, gas, and water[36]. Even though they are not that clear, the findings of the study underscore that these programs need to be redesigned to encourage new and existing small- and medium-sized hotels to implement environmentally friendly practices 
like the blue and the green flag, creativeness, energy efficiencies etc., at least to discourage nonenvironmental practices that do not affect customer satisfaction considerably.

\section{CONCLUSION}

The environmentally-friendly management practices in businesses can be good not only for environment but also for businesses themselves by reducing the operational costs that are redundant. Coherently, the determinants and effects of green business and green human resource management initiatives recently have gained a considerable research domain in the business and management literature.

In the hotel industry case, as hotels use the resources wisely by reducing the excessive consumption of water and energy and by minimizing the waste together with recycling them, they can gain from both lower costs and higher sustainability advantages. In some studies, contradicting the traditional wisdom predicting that environmentally-friendly practices expose new cost to the hotels, it is somewhat evidenced that hotels can be both green and profitable. Consistently, a new strand of research has focused on what motivate employees to behave green in the hotel industry in which there are some important cost items that can be saved by pro-environmental practices.

In line with the increasing interest, this study purposed to explore whether cost-saving green behaviors and motivations of employees working with cost- and/or profit-sharing plans differ from those who are paid constantly under cost- and/or profit-independent payment plans. The hypothesis was built on the theoretical expectation that employees within cost- and/or profit-sharing plans tend to be more provident and hereby eco-friendlier. To test the hypothesis, we collected survey data from 114 seasonal tourism employees working in 21 small- and medium-sized hotels located in Antalya, the largest city on the Mediterranean coast in Turkey, offering over 300 days of sunshine, fantastic beaches, resort towns, luxury hotels, and great shopping and therefore attracting many tourists from both other cities in Turkey and from abroad. In the survey, regarding the importance level of green practices to them, participants were asked to indicate their levels of agreement to each of the items about the importance of simple cost-saving and green hotel practices. Then whether the differences between two groups, namely those that work under a cost/profit sharing plan (Group 1) and those who are paid a constant amount which is independent of cost and profit(Group 2) were tested for significance by comparing the mean-scores of two groups through independent group paired t-test together with the analysis of variance.

There are several salient results found: The mean-scores in the items about paperless policy, non- smoking policy, placing green live plants on the property, setting temperature appropriately and using automatic and low- flow fixtures are high for both groups. The mean-scores of employees in Group 1 in the items about serving and having a proper portion of food, paperless policy, recycling water for reuse, and landscaping with native plants were found higher than those of Group 2. The only item that Group 2 has higher mean-score than that of Group 1 is about recycling. The overall difference between mean-scores of two groups was found statistically insignificant that implies a limited support to the hypothesis. Moreover, there was no significant difference found over demographics of the participants. This last evidence refers that age, education, gender, and working position do not matter for going green in this study's case.

Yet, there are signs indicating that employee payment plans reflecting the costs and profits of businesses can help in reducing the cost, and therefore, in increasing the profit. It can be inferred that cost-saving pro-environmental practices can benefit both environment and organizations. This suggestion provides new insights for scholars, managers/owners and policy-makers about what can be done for initiating and generalizing more sustainable, more responsible and greener management operations of businesses.

In Turkey, the touristic hotel industry is supported to some extent by governmental incentives as a part of the stimulating programs covering youth entrepreneurship and overall employment campaigns. Especially, small- and medium-sized enterprises in tourism sectors are getting benefits of lower rates in payment for utilities such as electricity, gas, and water. Even though being not that clear, the overall findings of the study underscore that these programs need to be redesigned to encourage hotels to implement environmentally-friendly practices, at least to discourage non-environmental practices that do not affect customer satisfaction considerably. 
The study suggests that in the whole industry case, beyond the traditional ranking criteria, hotels can be also certificated and licensed to be 'green managed' of 'green hotel' credentials to indicate they are managed eco-friendly such as the cases of blue flag and green flag accreditations. This kind proenvironmental awards based on strict criteria, no doubt, motivate hoteliers and mangers, together with their employees, to be involved in green management practices. Again, within the social responsibility and business sustainability contexts, business organizations need to take more initiatives in green business practices. Moreover, they can become both sustainable and profitable businesses without losing any gains and competitiveness. For accomplishing so, the study concludes that including employees in sharing costs and profits is somehow to have contributions to both organizations and environment. This conclusion sheds light on the current debates and future directions in the relevant literature.

\section{ACKNOWLEDGEMENT}

The author would like to thank anonymous hoteliers/managers, employees and guests for their collaborative participations.

\section{REFERENCES}

[1] Mbasera, M., Du Plessis, E., Saayman, M., and Kruger, M. (2016). Environmentally friendly practices in hotels. Acta Commercii-Independent Research Journal in the Management Science, 16(1), 1-8. http://dx.doi.org/ 10.4102/ac.v16i1.362

[2] Brocke, J., Seidel, S., \& Recker, J. (2012). Green business process management: Towards the sustainable enterprise. (Ed.), Berlin, Heidelberg: Springer.

[3] Dornfeld, D. A. (2013). Green manufacturing: Fundamentals and applications (Ed.), New York: Springer.

[4] Esty, D. C., and Winston, A. S. (2006). Green to gold: How smart companies use environmental strategy to innovate, create value, and build competitive advantage. New Haven and London: Yale University Press.

[5] Eccles, R. G., Perkins, K. M., and Serafeim, G. (2012). How to become a sustainable company. MIT Sloan Management Review, 53(4), 42-50.

[6] Mason, M., and Mason, R. D. (2012). Communicating a green corporate perspective: Ideological persuasion in the corporate environmental report. Journal of Business and Technical Communication, 26(4), 479-506. https://doi.org/10.1177/1050651912448872

[7] Barney J. (1991). Firm Resources and sustained competitive advantage. Journal of Management, 17 (1), 99-120.

[8] O'Shannassy, T. (2008). Sustainable competitive advantage or temporary competitive advantage: Improving understanding of an important strategy construct. Journal of Strategy and Management, 1(2), 168-180. https://doi.org/10.1108/17554250810926357

[9] Clarke, R. A., Stavins R. N., Greeno, J. L., Bavaria, J. L., Cairncross, F., Esty, D. C., Smart, B., Piet, J., Wells, R. P., Gray, R., Fischer K., and Schot, J. (1994). The challenge of going green. Harvard Business Review, July-August, https://hbr.org/1994/07/the-challenge-of-going-green

[10] Ambec, S., and Lanoie, P. (2008). Does it pay to be green? A systematic overview. Academy of Management Perspectives,

[11] Zengeni, N., Zengeni, D. M. F., and Muzambi, S. (2013). Hoteliers' perceptions of the impacts of green tourism on hotel operating costs in Zimbabwe: The case of selected Harare hotels. Australian Journal of Business and Management Research, 2(11), 64-73.

[12] UNWTO-The World Tourism Organization (2016). 2016 Annual Report. http://cf.cdn.unwto.org/ sites/all/ files/pdf/annual_report_2016_web_0.pdf

[13] EcoHotels (2017). http://green.hotelscombined.com/index.php

[14] D'Amato, A., Henderson, S., and Florence, S. (2009). Corporate social responsibility and sustainable business: A guide to leadership tasks and functions. Center for Creative Leadership, Greensboro/North Carolina: CCL Press.

[15] Glavas A., Kelley, K. (2014). The effects of perceived corporate social responsibility on employees. Business Ethics Quarterly, 24(2), 165-202. https://doi.org/10.5840/beq20143206

[16] Shrivastava, P. (1995). The role of corporations in achieving ecological sustainability. Academy of Management Review, 20(4), 936-960. http://dx.doi.org/10.5465/AMR.1995.9512280026

[17] Wales, T. (2013). Organizational Sustainability: What is it, and why does it matter? Review of Enterprise and Management Studies, 1(1), 38-49. 
Cost-Sharing Payment Plans and Cost-Saving Green Management Practices: The Case of Seasonal Employees in Turkey's Small- and Medium-Sized Touristic Hotels

[18] Čekanavičius, L., Bazytė, R., and Dičmonaitè, A. (2014). Green business: Challenges and practices. Ekonomika, 93(1), 74-88.

[19] Newton, T., and Harte, G. (1997). Green business: Technicist Kitsch? Journal of Management Studies, 34(1), 75-98. http://dx.doi.org/10.1111/1467-6486.00043

[20] Bohdanowicz, P. (2006). Environmental awareness and initiatives in the Swedish and Polish hotel industries-Survey results. International Journal of Hospitality Management, 25(4), 662-668. https://doi.org/10.1016/j.ijhm.2005.06.006

[21] Ahmad, S. (2015). Green human resource management: Policies and practices. Cogent Business \& Management, 2(1), 1-13, https://doi.org/10.1080/23311975.2015.1030817

[22] Ones, D. S., Dilchert, S. (2012). Employee green behaviors. In Jackson, S. E., Ones, D. S., Dilchert, S. (Eds.), Managing human resources for environmental sustainability (pp. 85-116). New York, NY: Jossey Bass.

[23] Renwick, D. W.S., Redman, T. and Maguire, S. (2013). Green human resource management: A review and research agenda. International Journal of Management Reviews, 15(1), 1-14. http://dx.doi.org/10.1111/j.1468-2370.2011.00328.x

[24] Shen, J., Dumont, J., and Deng, X. (2016). Employees' perceptions of green HRM and non-green employee work outcomes: The social identity and stakeholder perspectives. Group \& Organization Management (Online first), https://doi.org/10.1177/1059601116664610

[25] Kruse, D. L. (1996). Why do firms adopt profit-sharing and employee ownership plans? British Journal of Industrial Relations: An International Journal of Employment Relations, 34(4), 515-538. https://doi.org/10.1111/j.1467-8543.1996.tb00488.x

[26] Wagner, J. A., and Hollenbeck, J. R. (2015). Organizational behavior: Securing competitive advantage. $2^{\text {nd }}$ Ed., New York: Routledge.

[27] Graci, S., and Kuehnel, J. (2011). How to increase your bottom line by going green. Green Hotels \& Responsible Tourism Initiative. http://green.hotelscombined.com/Pages/MainGreen/Downloads/greenhotel-whitepaper.pdf

[28] TURSAB-Association of Turkish Travel Agencies (2017). https://www.tursab.org.tr/en

[29] Chang, W. Y., and Chang, I. Y. (2013). An investigation of students' motivation to learn and learning attitude affect the learning effect: A case study on tourism management students. The Anthropologist, 16(3), 457-463.

[30] Kirk, D. (1995). Environmental management in hotels. International Journal of Contemporary Hospitality Management, 7(6), 3-8, https://doi.org/10.1108/09596119510095325

[31] Han, H., Hsu, J. and Sheu, C. (2010). Application of the theory of planned behavior to green hotel choice: Testing the effect of environmental friendly activities. Tourism Management 31(3), 325-334. http://dx.doi.org /10.1016/j.tourman.2009.03.013

[32] Drury, C. (2005). Management accounting for business. $3^{\text {rd }}$ Ed., London: Thomson Learning.

[33] Bohdanowicz, P. (2005). European hoteliers' environmental attitudes: Greening the business. Cornell Hotel and Restaurant Administration Quarterly, 46(2), 188-204. https://doi.org/10.1177/0010880 404273891

[34] Kim, S. H. (2009). An investigation into hotel employees' perception of green practices. Master Thesis of Science in Tourism and Hospitality Management. Orlando: The University of Central Florida, the Rosen College of Hospitality Management. http://etd.fcla.edu/CF/CFE0002908/Kim_Sun-Hwa_200912_MS.pdf

[35] Kim, S. H. and Choi, Y. (2013). Hotel employees' perception of green practices. International Journal of Hospitality \& Tourism Administration, 14(3), 157-178. https://doi.org/10.1080/15256480.2013.782220

[36] Republic of Turkey, Ministry of Culture and Tourism (2017). http://www.kultur.gov.tr/?_dil=2

Citation: Özge Demiral. " Cost-Sharing Payment Plans and Cost-Saving Green Management Practices: The Case of Seasonal Employees in Turkey's Small-and Medium-Sized Touristic Hotels "International Journal of Managerial Studies and Research (IJMSR), vol 5, no. 12, 2017, pp. 35-45. doi:http://dx.doi.org/10.20431/2349-0349.0512005.

Copyright: () 2017 Authors. This is an open-access article distributed under the terms of the Creative Commons Attribution License, which permits unrestricted use, distribution, and reproduction in any medium, provided the original author and source are credited. 